MONTANA

STATE UNIVERSITY

LIBRARY

\title{
Let's Talk Online Video Pilot Results
}

\author{
Author: Kenneth Flagg, Jordan Schupbach, Lillian Lin
}

[This is the abstract of a report prepared for Sarah Keller, a professor at MSU Billings.]

Published October 15 $5^{\text {th }}, 2018$ based on a report from March 31, 2017

Made available through Montana State University's $\underline{\text { ScholarWorks }}$

scholarworks.montana.edu 


\title{
Let's Talk Online Video Pilot Results
}

\author{
Kenneth Flagg* \\ Jordan Schupbach \\ Lillian Lin \\ Montana State University \\ Statistical Consulting and Research Services
}

Background: Montana has the highest suicide rate in the nation, with 26 deaths from suicide per 100,000. To address this threat, young adults were recruited to perform community-based theatre projects about the importance of seeking professional help for depression and thoughts of suicide. This study examined the effectiveness of two short documentaries that were based on the Let's Talk theatre intervention in reducing stigma of help-seeking.

Methods: 87 students at a college in Billings, Montana were randomly assigned to two interventions and one control group during the 2016-17 school year. Self-administered questionnaires were completed by students in all groups at baseline and approximately 2 weeks after program implementation.

Results: 38 students completed both the baseline and follow-up questionnaires (a 44\% follow-up rate). Lower rates of self-stigma of seeking help (SSOSH) were observed among students in the longer format intervention group. For respondents in that intervention group, we estimate the mean SSOSH score decrease to be $4.16(\mathrm{SE}=1.67)$ more than the mean score decrease for individuals in the control group $(\mathrm{P}=0.017)$. There was no evidence that the students' race/ethnicity, grade, and gender altered the impact of the intervention on any of the outcomes assessed in this analysis.

Conclusion: This study provides preliminary analysis of the intervention, but further evaluations are needed with a larger and more racially and socio-economically diverse sample. Let's Talk continues to be a unique, narrative-based suicide prevention program with demonstrated effects on self-reported stigma of help-seeking in a study utilizing a randomized experimental design.

Acknowledgements: Research reported in this publication was supported by Institutional Development Awards (IDeA) from the National Institute of General Medical Sciences of the National Institutes of Health under Awards P20GM103474, 5U54GM104944, U54GM115371, and 5P20GM104417. The content is solely the responsibility of the authors and does not necessarily represent the official views of the National Institutes of Health.

*Correspondence: Kenneth Flagg, , Department of Mathematical Sciences, Montana State University, P.O. Box 172400, Bozeman, MT 59717-2400, www.montana.edu/statisticalconsulting 